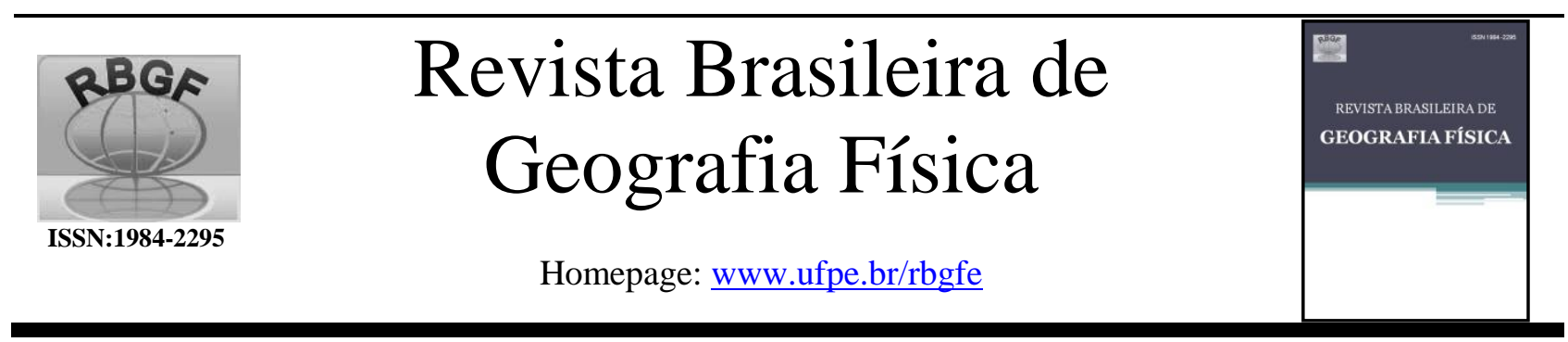

\title{
Análise da sustentabilidade em áreas de expansão urbana: um estudo em loteamentos da cidade de Francisco Beltrão-PR
}

\author{
Mônica Aparecida Gonçalves Scatola ${ }^{1}$, Julio Caetano Tomazoni²
}

\begin{abstract}
${ }^{1}$ Mestre em Desenvolvimento Regional, UTFPR, Arquiteta e Urbanista, Autor correspondente: e-mail: arquitetura.monica@ hotmail.com;

${ }^{2}$ Docente do Programa de Pós-Graduação em Desenvolvimento Regional, da UTFPR - Campus Pato Branco. Doutor em Geologia (UFPR-2003). E-mail caetano@utfpr.edu.br.
\end{abstract}

Artigo recebido em 24/01/2018 e aceito em 08/07/2018

\section{R E S U M O}

Este artigo apresenta um estudo sobre a presença de sustentabilidade em áreas de expansão territorial urbana na cidade de Francisco Beltrão-PR, através do estudo de três loteamentos implantados na cidade em meados do ano 2010. O estudo utiliza como parâmetro as categorias de sustentabilidade oriundas do Estatuto da Cidade, que são terra urbana, moradia, saneamento ambiental, infraestrutura, transporte, serviços públicos e lazer, sendo definidos indicadores de sustentabilidade a fim de avaliar cada categoria citada. Como resultado, apontam-se deficiências na presença de sustentabilidade com relação a algumas categorias, e bons níveis de sustentabilidade com relação a outras, havendo também diferenças entre os loteamentos analisados. Concluise que a aferição da sustentabilidade urbana através de indicadores é necessária para melhorar a qualidade de vida das pessoas na atualidade, e propiciar áreas urbanas adequadas visando as gerações futuras. Todavia a análise da sustentabilidade deves empre levar em consideração as particularidades locais.

Palavras-Chave: sustentabilidade urbana; indicadores de sustentabilidade; expansão territorial urbana; planejamento urbano.

\section{Analysis of sustainability in areas of urban expansion: a study in subdivisions of the city of Francisco Beltrão-PR}

\section{A B S T R A C T}

This paperpresents a study about the presence of sustainability in areas of urban territorial expansion in the city of Francisco Beltrão-PR, through the analysis of three land parcels implanted in the city in the middle of 2010. The study uses as a parameter the categories of sustainability of the City Statute, which are urban land, housing, environmental sanitation, infrastructure, transportation, public services and leisure, and sustainability indicators are defined in order to evaluate each category. As a result, there are deficiencies in the presence of sustainability in relation to some categories, and good levels of sustainability in relation to others, and there are also differences among the lots analyzed. It is concluded that the measurement of urban sustainability through indicators is necessary to improve people's quality of life today, and to provide adequate urban areas for future generations, but sustainability analysis should always take into account local particularities.

Keywords: urban sustainability; sustainability indicators; urban territorial expansion; urban planning.

Scatola, M. A. G., Tomazoni, J. C. 


\section{Introdução}

A partir dos anos 1980 até o início da década de 2010, a cidade de Francisco Beltrão-PR, vivenciou os efeitos de um crescente processo de expansão de sua malha urbana, sendo o mesmo decorrente de fatores diversos, dentre os quais se pode exemplificar: o esvaziamento de pequenas propriedades rurais em municípios da região e também em Francisco Beltrão, gerando a migração campo-cidade; a oferta de comércio e serviços no município; também o aumento da oferta de crédito imobiliário para financiamentos habitacionais, sobretudo através de programas do governo federal, visando o incentivo ao desenvolvimento do setor da construção civil e a infraestrutura. Estes fatores se ligam intimamente às facetas da expansão territorial urbana local, e constituem partes do movimento que acerta ao processo de reprodução da cidade como um centro urbano regional (Fresca, 2010), o que também reflete na expansão de sua malha urbana, principalmente através de novos loteamentos implantados.

As discussões sobre sustentabilidade são impulsionadas, por sua vez, a partir das Conferências das Nações Unidas para o Meio Ambiente e Desenvolvimento, principalmente a que ocorreu na Suécia em 1972, quando o termo "sustentabilidade" passou a ser inicialmente debatido, e a Conferência no Rio de Janeiro em 1992, quando os conceitos de aplicação e avaliação da sustentabilidade são lançados, e surge a Agenda 21.

No Brasil, os debates sobre a sustentabilidade do espaço urbano passam a ser mais efetivos através da publicação da Lei Federal $\mathrm{n}^{\mathrm{o}}$ 10.257/2001, o Estatuto da Cidade (Brasil, 2001), a qual regulamenta os artigos sobre política urbana da Constituição Federal, e através da qual são efetivados instrumentos como os Planos Diretores, os quais se tornam os grandes responsáveis por operacionalizar as ações de planejamento urbano e urbanismo, e nos quais os parâmetros de sustentabilidade urbana trazidos pelo Estatuto da Cidade, devem estar incorporados.

Diante do quadro de desenvolvimento e da importância da sustentabilidade urbana, e diante da expansão da malha urbana de Francisco Beltrão nos últimos anos, pretende-se através deste artigo, analisar a presença de categorias de sustentabilidade em loteamentos da expansão urbana recente de Francisco Beltrão-PR, através da escolha e avaliação de indicadores de sustentabilidade nestes locais.

Nesta análise sobre a sustentabilidade urbana, as categorias de sustentabilidade presentes no Estatuto da Cidade, que são terra urbana, moradia, saneamento ambiental, infraestrutura urbana, serviços públicos, trabalho e lazer, são utilizadas a fim de levantar os principais indicadores que definem cada categoria, os quais são analisados em três loteamentos que caracterizam diferentes regiões da expansão territorial recente de Francisco Beltrão, sendo estes os loteamentos São Cristóvão, na região Sul, Lago das Torres, na região Leste, e Marchiori, na região Norte da malha urbana local.

O método para a análise de cada indicador de sustentabilidade escolhido se baseou em estudos de sustentabilidade mencionados por Mascaró (2005) e Farr (2013), a fim de considerar diferentes aspectos para o estudo de cada indicador de sustentabilidade, os quais apresentam características diferentes, porém expressam em sua totalidade, se há sustentabilidade nas áreas de expansão analisadas.

Scatola, M. A. G., Tomazoni, J. C. 


\section{Panorama e Importância da Sustentabilidade nos}

\section{Espaços Urbanos}

O termo sustentabilidade se difundiu principalmente a partir dos anos1970, 1980 1990, quando diversos debates sobre o tema aconteceram a nível mundial, principalmente através das arenas de discussões a respeito da temática ambiental, na Eco 72, na Eco 92 em 1992, e na RIO+20, no ano 2012.

Ao tratar-se do espaço urbano, todavia, se pode afirmar que as discussões por cidades mais sustentáveis ainda são bastante recentes, como se pode exemplificar, no Brasil, através do Estatuto da Cidade, o qual foi publicado somente no ano 2001, foi a primeira política urbana que definiu o que seria sustentabilidade para as cidades brasileiras.

Para um entendimento sobre a sustentabilidade para os espaços urbanos, todavia, não se pode deixar de citar as cidades originadas da Revolução Industrial, entre os séculos XIX e XX, a partir das quais se passou a pensar os espaços urbanos através de questões de ordem sociológica, através do legado dos pensadores pré-urbanistas, e também questões de ordem técnica e estudos de caso projetuais, através do legado dos autores urbanistas (Choay, 2010). O pensar, planejar e urbanizar a cidade industrial, foram atosvoltados principalmente a questões de higiene, salubridade, ordenamento, beleza e funcionalidade das cidades caóticas do período, as quais se originaram principalmente pela explosão demográfica nos centros urbanos, em uma sociedade antes essencialmente agrícola.

As questões que nortearam o pensar a cidade do final do século XIX e início do século $\mathrm{XX}$, se aplicaram em um campo no qual o desenvolvimento rápido, aliado à pujança econômica, eram essenciais. É neste panorama ainda que se desenvolvem as cidades do presente, agora voltadas também à questões de ordem sustentável, ou seja, da capacidade dos centros urbanos atuais de continuar se desenvolvendo e tendo vigor econômico, porém com vistas à manutenção dos recursos existentes, para que sirvam também às futuras gerações.

A cidade do presente passa a deixar de lado o utilitarismo exacerbado a fim de aplicar as premissas da sustentabilidade. Afinal, de acordo com Leite e Award (2012, p. 04) "[...] se o século 19 foi dos impérios e o 20, das nações, este é o século das cidades. $\mathrm{E}$ as imensas inovações que ora se anunciam ocorrerão no território urbano”.

O fato é que o início do século 21 trouxe o desafio do desenvolvimento sustentável, que busca aliar o desenvolvimento econômico ao não esgotamento dos recursos naturais. $\mathrm{O}$ primeiro conceito de desenvolvimento sustentável foi abordado através do relatório "Nosso Futuro Comum", de 1987, desenvolvido pela Comissão Mundial de Meio Ambiente e Desenvolvimento das Nações Unidas (Leite e Award, 2012), e definia o termo como aquele que satisfaz as necessidades presentes, sem comprometer a capacidade das gerações futuras de suprir suas próprias necessidades. O relatório, com suas definições decisivas a respeito da sustentabilidade, foi fruto de discussões sobre o tema que se iniciaram desde a Eco 72, porém seu ápice foi na Eco 92 no Rio de Janeiro.

O conceito geral de sustentabilidade surgiu da percepção de que os recursos naturais necessários às atividades do homem, não provém de fontes infinitas, e caso estes sejam utilizados sem levar-se em consideração sua escassez, haverá uma quebra do sistema pela falta dos mesmos, e 
consequentemente graves problemas para toda a população mundial. Já a sustentabilidade urbana, leva em consideração esta mesma percepção, todavia sob a perspectiva das cidades, e de que forma os responsáveis pelas modificações nos espaços urbanos, podem agir a fim de promover a sustentabilidade no espaço urbano, contribuindo assim com a aplicação da mesma em escala mundial, uma vez que a maior parte dos problemas ambientais, bem como a maior parcela de população afetada pelos mesmos, se encontram nas cidades.

Pensar a sustentabilidade da urbanização nas cidades atuais não se faz uma verdade inconveniente, como muitos agentes responsáveis pela reprodução das cidades, preferem pensar. De acordo com Farr (2013), até mesmo líderes progressistas agora passam a defender um equilíbrio entre as necessidades da humanidade, tanto sociais quanto econômicas, e as necessidades da natureza, reconhecendo o poder do urbanismo consciente para induzir as pessoas a optar por um estilo de vida que respeite os recursos disponíveis, com economia destes. Ao mesmo tempo, o autor cita que "toda sustentabilidade é local" (Farr, 2013, p.13), referindo-se à necessidade de analisar as peculiaridades de cada cidade a fim de implantar as caracterizações ideais de um urbanismo sustentável.

O diálogo da sustentabilidade no Urbanismo entra em questão justamente nesta necessidade por repensar como são constituídas, como crescem e se desenvolvem as cidades, o que deve acontecer de acordo com estratégias com vistas ao desenvolvimento com respeito aos aspectos ambientais. Nesta perspectiva, a resposta para a urbanização sustentável é a utilização consciente do ambiente evitando o desperdício, principalmente da água, solo e ar, que são os meios mais contaminados pela utilização irracional dos recursos. Para que uma urbanização sustentável aconteça, portanto, deve ocorrer uma reforma do desenho urbano pautada em uma urbanização servida pelo transporte público, incentivando as pessoas a caminharem, integrando a edificações e infraestrutura de alto desempenho. Na urbanização sustentável, se deve agir conforme o princípio da precaução, trazendo à tona o conceito de cidades resilientes, preparadas em sua estrutura física e social, para enfrentar situações de risco (Farr, 2013).

Ainda de acordo com Farr (2013), algumas medidas que podem ser tomadas para o alcance de uma urbanização sustentável são as seguintes: criar uma gama de escolhas de habitação; bairros com espaço para passeio, nos quais as pessoas sejam incentivadas a caminhar; estimular a participação da comunidade nas decisões sobre o contexto urbano imediato; incentivar o senso de lugar, proporcionando cidades com alma, nas quais os cidadãos se reconheçam como tal; decisões urbanas econômicas; mistura de usos do solo; preservar espaços abertos; variedade na escolha pela mobilidade urbana; reforçar o adensamento das cidades, bem como revitalizar áreas existentes que possam ser reurbanizadas, antes de assimilar novos espaços; bem como utilizar construções compactas.

Ao mesmo tempo, certamente nem todas as características acima citadas podem ser generalizadas e utilizadas em qualquer espaço urbano, pois é preciso compreender a vontade subjetiva de elementos do público local, para só então definir o que seria uma urbanização sustentável, respeitando-se o ideal de que a mesma acontece de maneira pontual, levando-se em 
consideração as particularidades dos espaços urbanos, sendo neste ponto importante a aplicação de indicadores de sustentabilidade adequados, os quais tomem partido das estruturas físicas e sociais de determinado local.

Ao abordar a mensuração da sustentabilidade, percebe-se que ocorreu uma evolução dos indicadores de sustentabilidade, os quais surgiram a partir de aferições do campo da economia, tal como PNB (Produto Nacional Bruto) ou PIB (Produto Interno Bruto), e mais tarde a Medida de bem-estar econômico, que evoluiu para a Medida de bem-estar econômico sustentável (Veiga, 2010). Os indicadores tiveram atribuições iniciais de contabilidade convencional, e aos poucos foram agregando componentes voltados para o bem-estar.

$\mathrm{Na}$ atualidade, para a mensuração da sustentabilidade urbana, se faz importante utilizar indicadores que trabalhem com as diversas dimensões dentro da temática qualidade de vida, pois se não houver qualidade de vida, provavelmente a sustentabilidade urbana dificilmente subsistirá. Através de indicadores como qualidade ambiental (domicílios servidos por água, esgoto, coleta de lixo adequada), condições de habitação e qualidade dos domicílios (garantia de moradia, potencial de atração de investimentos públicos), serviços sociais (acesso a equipamentos públicos urbanos), dentre outras categorias e indicadores mais voltados aos aspectos sociais, aliados à abordagem técnica, se faz possível construir um bom prospecto de indicadores.

Ao mesmo tempo, cada cidade, ou mesmo cada bairro dentro de uma cidade, pode possuir características específicas, por isso surge a necessidade por utilizar os indicadores pontualmente. Assim, para a análise da sustentabilidade urbana, é necessário que se leve em consideração particularidades de diferentes locais de um espaço urbano, a fim de qualificar as condições de sustentabilidade em determinada cidade, levando-se em consideração características de ordem social e técnica, e também o diálogo com a comunidade local (Koga, 2011).

\section{O Método para a Análise da Sustentabilidade em Loteamentos de Francisco Beltrão-Pr}

A pesquisa se fundamenta na análise de indicadores de sustentabilidade em áreas de expansão do espaço urbano de Francisco BeltrãoPR, através de categorias ou temas de sustentabilidade elencadas pela Lei Federal $n^{\circ}$ 10.257/2001, o Estatuto da Cidade, que cita terra urbana, moradia, saneamento ambiental, transportes, serviços públicos e lazer, como sendo o entendimento de sustentabilidade.

As categorias acima citadas foram escolhidas por estarem expressas em uma Lei Federal de extrema importância para as cidades atuais, uma vez que a partir desta Lei, muitos Planos Diretores são revisados ou elaborados nas cidades brasileiras, inclusive em Francisco Beltrão, cujo Plano Diretor existente, o qual datava do ano 1996, foi revisado no ano 2006 à luz do Estatuto da Cidade. Entende-se, desta forma, que as categorias de sustentabilidade urbana devem estar neste expressas, e aplicadas nos loteamentos que configuram áreas de expansão territorial urbana.

Para a análise destes indicadores nos loteamentos em estudo, utilizam-se os estudos desenvolvidos por Mascaró (2005) e Farr (2013). 
Categorias de sustentabilidade a partir do Estatuto da Cidade e seus indicadores

O Estatuto da Cidade, ou Lei Federal $n^{\circ}$ $10.257 / 2001$, teve seu projeto de Lei $\mathrm{n}^{\circ} 181$ proposto no ano 1989, fruto da Agenda da reforma urbana no Brasil. Na década de 1990, todavia, os debates sobre o Estatuto recebem a influência da Agenda da sustentabilidade através da publicação da Agenda 21, e o Estatuto é finalmente aprovado em 2001, após longos anos de debates e a sustentabilidade incorporada ao seu texto (Braga, 2012).

A definição geral de cidades sustentáveis, de acordo com o Estatuto da Cidade, é uma representação do direito à cidade, através das categorias de sustentabilidade urbana: terra urbana, moradia, saneamento ambiental, infraestrutura urbana, transporte, serviços públicos, trabalho e lazer (Brasil, 2001).

Neste trabalho, portanto, propõe-se como método partir das categorias de sustentabilidade citadas, definindo indicadores de sustentabilidade que podem representar cada categoria, aplicando estes indicadores nos espaços urbanos em estudo.

\section{Terra Urbana}

Para Corrêa (1995), são os diferentes usos da terra que definem o próprio espaço urbano, ou seja, o tema terra urbana está diretamente ligado à urbanização e desenvolvimento dos espaços urbanos, por isso da importância em estudar de que forma o aproveitamento deste recurso natural acontece nos dias atuais, principalmente junto a áreas de expansão do espaço urbano.

A terra urbana é uma categoria ampla a ser estudada, e pode compreender temas tais como a geomorfologia, através da descrição de tipos e padrões de relevo, padrões de drenagem, altitude, declividade, processos de erosão e acumulação, bem como fragilidades e potencialidades da terra; a pedologia, através dos estudos dos tipos de solo, sua vulnerabilidade à erosão e potencial e restrições de uso; também quanto ao uso e ocupação das terras, e pela proteção da terra pelas camadas de vegetação existentes sobre a mesma, assim como as edificações existentes podem ser elencadas na análise de uso e ocupação das terras urbanas (Santos, 2004).

Para a análise da terra urbana nos loteamentos do estudo, o foco estará na declividade dos terrenos dos loteamentos, comparando às temáticas erosão e restrição de uso. Esta análise se dará através da utilização do Sistema de Informação Geográfica (SIG) Spring 5.4, com o objetivo de gerar imagens destacando as áreas em risco potencial, levando-se em consideração as recomendações legais, que são a proibição dos loteamentos em áreas com mais de 30\% de inclinação, bem como a ocupação de topos de morro acima de 20 metros a partir do logradouro lindeiro.

\section{Moradia: lotes}

O espaço urbano possui diferentes elementos estruturantes, os quais em conjunto possibilitam o entendimento do todo urbano, e a estes se denomina elementos morfológicos do espaço urbano. Os lotes são um destes elementos, e constituem a base do assentamento das moradias, ao mesmo tempo em que configuram a forma de adaptação da terra urbana aos usos aos quais será destinada, sendo importante uma vez que estabelece as conexões entre espaços abertos e fechados, públicos e privados. O lote caracteriza também a unidade em que parte do ambiente

Scatola, M. A. G., Tomazoni, J. C. 
natural, é fracionada e transformada para atender ao processo de urbanização, e embora seja norteado por leis, sendo uma porção cadastral no espaço urbano, se constitui como o fundamento do elemento edificado, que abriga as atividades do homem (Lamas, 2014), e auxilia na definição de aspectos relacionados à moradia.

Para a análise dos lotes no quesito moradia, será confeccionado um mapa de declividade da gleba, e sua relação com a disposição dos terrenos. Esta análise se realiza com base na confrontação do mapa de declividade dos loteamentos, e a disposição dos mesmos no loteamento, através de mapas gerados com o software Spring 5.4, e a confecção da tabela de acordo com as morfologias destes lotes.

\section{Saneamento Ambiental}

O saneamento ambiental se relaciona, de acordo com o Ministério das Cidades (2004), a ações técnicas e socioeconômicas entendidas como fundamentalmente de saúde pública, objetivando alcançar níveis crescentes de salubridade ambiental, melhorando as condições de vida da população urbana e rural.

De fato, as questões relativas ao saneamento ambiental são geralmente voltadas à preservação da saúde das pessoas, melhorando assim sua qualidade de vida, uma vez que a falta de saneamento provoca, de maneira direta, diversos agravantes e poluição ambiental, o que acaba impactando as populações, principalmente em áreas urbanas.

O saneamento ambiental, que também é denominado de saneamento básico devido ao caráter primordial de sua oferta, se relaciona com questões de oferta de água potável, esgotamento sanitário, coleta, tratamento e disposição de resíduos sólidos, e da drenagem do ambiente das águas, serviços públicos essenciais ao bom funcionamento do espaço urbano (Brasil, 2007).

Para este indicador, serão utilizados dados obtidos junto aos órgãos municipais, e o cálculo será realizado através do método explicitado na tabela 01 . O objetivo deste indicador é compreender qual o percentual de edificações do loteamento que são atendidas por sistema adequado de esgotamento sanitário, entendido este como rede de coleta de esgotos, sendo considerados aqui outros sistemas como fossa séptica ou outros, inadequados devido à facilidade de contaminação do solo e lençol freático.

Tabela 01: Obtenção do percentual de área atendida por sistema de coleta de esgotos.

\begin{tabular}{|c|c|c|}
\hline $\begin{array}{l}\text { Sistema de coleta de } \\
\text { esgotos }\end{array}$ & Casas & Porcentagem \\
\hline Rede de coleta & $\mathrm{X}$ & $\mathrm{x} /(\mathrm{x}+\mathrm{y})$ \\
\hline Fossa séptica ou outro & Y & $y /(x+y)$ \\
\hline Total & $x+y$ & \\
\hline
\end{tabular}

\section{Infraestrutura Urbana}

Entende-se como infraestrutura urbana, um conjunto de sistemas técnicos e serviços responsáveis por suportar as funções urbanas, tais como as redes de saneamento ambiental (esgotamento sanitário, e drenagem pluvial), o transporte, obras viárias, vias, equipamentos públicos diversos, serviços de fornecimento de energia residencial e urbana, serviços de telecomunicações, dentre outros (Duarte, 2011).

A disposição da infraestrutura é uma etapa básica no processo de urbanização, pois parte dos serviços de infraestrutura, correspondem às etapas iniciais do parcelamento do solo, como o fornecimento de água potável, a disposição de redes de energia elétrica, iluminação pública, 
drenagem das águas, abertura e pavimentação das vias, dentre outros.

De acordo com Benitez (1998, p.124), a infraestrutura é "a parte do capital global, que combina e associa a simbologia do capital e do público". Daí se originam os meios técnicos e serviços de transporte, abastecimento de energia, sistema de comunicações, redes de água e esgoto, instituições de ensino, órgãos de saúde, instalações de segurança, entre outros. Essa combinação se dá devido à infraestrutura ser parte do capital que se destina à população, adquirindo assim o caráter público, destinado a todos.

$\mathrm{Na}$ análise de infraestrutura urbana neste estudo, optou-se por utilizar o indicador iluminação pública, uma vez entendido que os sistemas de iluminação pública urbana são essenciais para a segurança e bem estar dos moradores no espaço urbano, principalmente no período noturno, além da seguridade viária, citadina, a orientação visual, a promoção do ambiente, identidade e recreação (Manzano, 2006). Levando-se em consideração este aspecto, analisou-se a disponibilidade de sistemas de iluminação nos loteamentos do estudo, através da obtenção do percentual de ruas com iluminação adequada dentre as ruas do loteamento, o qual é demonstrado pela equação 01 .

Ao mesmo tempo, serão aferidas através de pesquisa de campo, as distâncias entre os pontos de iluminação, a fim de observar se estão de acordo com as distâncias recomendadas de 30 a 45 metros para postes com iluminação convencional, de acordo com Mascaró e Yoshinaga (2013).

Indicador $=$

$\frac{\text { Totalderuascomiluminaçãopública }}{\text { Totalderuasdoloteamento }}$ Equação 01

Fonte: Mascaró (2005), adaptado pelos autores.

\section{Transportes}

Quando se fala a respeito do transporte, logo se remete ao transporte coletivo público, pois o mesmo constitui, nas cidades atuais, um meio sustentável de locomoção evitando o congestionamento dos espaços urbanos. O transporte coletivo público visa garantir aos cidadãos o acesso à cidade, seus equipamentos urbanos essenciais e serviços públicos, pois as rotas traçadas geralmente visam atender a eixos de ligação entre as habitações e o acesso aos serviços e equipamentos do espaço urbano (Duarte, 2011).

Ao mesmo tempo, levando-se em consideração um período mais atual, de desestabilização econômica no Brasil, somando-se aos novos olhares da sociedade sobre as questões do espaço urbano com ênfase na aplicação de uma real sustentabilidade, surge a necessidade por cidades cujos espaços sejam mais integrados através de questões de mobilidade urbana, a qual deve ser implementada tanto através de um transporte público coletivo adequado, bem como através de rotas para ciclistas e cidades incentivadoras dos percursos feitos a pé pelos cidadãos.

Neste estudo, portanto, optou-se por analisar, para a categoria de sustentabilidade em relação ao transporte, o indicador relacionado à utilização de meio de transporte não motorizado, e a utilização do transporte público coletivo. Com estes indicadores, avalia-se o percentual de usuários que utilizam meios de transporte considerados sustentáveis. A obtenção destes indicadores se da através da aplicação de entrevista aos usuários dos loteamentos, e os dados são comparados ao total de habitantes dos loteamentos.

\section{Serviços Públicos e Lazer}


A oferta de serviços públicos está atrelada ao conceito da oferta de equipamentos públicos urbanos voltados aos diversos serviços que o governo deve prestar à população, sendo estes direitos garantidos pela própria Constituição Federal, através primeiramente do Art. $6^{\circ}$, que dispõe sobre os direitos sociais: "são direitos sociais a educação, saúde, alimentação, o trabalho, a moradia, o lazer, a segurança, a previdência social, a proteção à maternidade e à infância, a assistência aos desamparados [...]" (Brasil, 1988, p.05).

Dispor de serviços públicos significa disponibilizar de uma rede de equipamentos públicos permanentes junto ao espaço urbano, nos quais os serviços públicos citados na constituição, bem como demais serviços necessários, possam ser efetivados, a exemplo de escolas, creches e serviços educacionais diversos, centros cívicos, centros esportivos e de recreação públicos, biblioteca, delegacia de polícia e postos de bombeiros, agências de correios, hospitais, postos de saúde e de atendimentos de emergência, serviços ligados à justiça, aos órgãos da administração pública, dentre outros.

A fim de efetuar esta análise, são confeccionados mapas dos bairros nos quais os loteamentos em estudo estão localizados, e são demarcados nestes mapas a localização dos equipamentos de saúde, educacionais, de lazer, além de possíveis destinos cotidianos, sendo delimitados raios de abrangência máxima destes equipamentos, que variam de 400 metros para os equipamentos educacionais e de lazer, a 800 metros

\footnotetext{
${ }^{1}$ De acordo com pesquisa realizada em agosto de 2016, junto ao Departamento de Urbanismo da Prefeitura Municipal de Francisco Beltrão.
}

para equipamentos de saúde. No mesmo mapa, são demarcados uma série de possíveis destinos cotidianos, considerando-se também o raio de abrangência de 400 metros.

Todavia, não basta que se analise sob o viés da sustentabilidade somente a oferta de equipamentos públicos, uma vez que equipamentos de serviços cotidianos também devem ser ofertados à população, tal como banco, cabeleireiro, farmácia, igrejas, delegacia, restaurante e supermercado, a fim de identificar o nível de completude do bairro, e a localização dos loteamentos, com relação à existência de equipamentos.

\section{Seleção dos loteamentos para o estudo}

Entre o ano de 2002 a 2015, cerca de 66 novos loteamentos foram aprovados para serem implantados junto à malha urbana do município de Francisco Beltrão ${ }^{1}$, sendo que dentre os loteamentos aprovados no período, foram selecionados três loteamentos para compor este estudo, de acordo com parâmetros de implantação dos mesmos junto à malha urbana local, possibilitando que diferentes áreas de expansão urbana recente do local pudessem ser analisadas sob o viés da sustentabilidade. Ao mesmo tempo, tomou-se o cuidado na escolha de loteamentos com padrões diferentes, tanto na configuração do sítio quanto na caracterização socioeconômica destes loteamentos, para que assim a análise final deste estudo pudesse elencar diferentes fatores que podem ou não influenciar na presença de características sustentáveis. A figura 01 demonstra

Scatola, M. A. G., Tomazoni, J. C. 
a localização dos loteamentos no perímetro urbano de Francisco Beltrão.

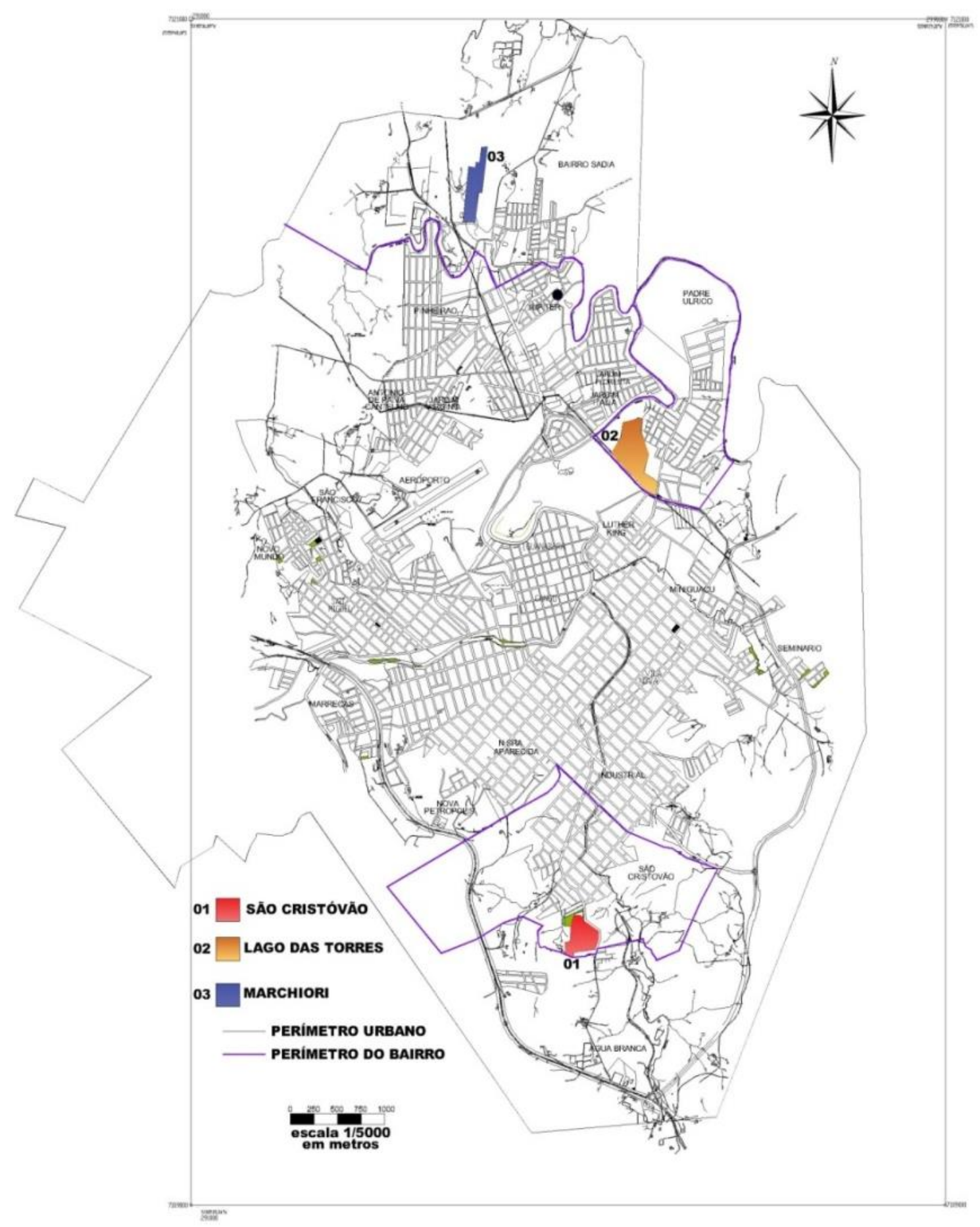

Figura 01: Localização dos loteamentos no perímetro urbano de Francisco Beltrão.

Fonte: Mapa fornecido pela Prefeitura Municipal de Francisco Beltrão. (Editado pelos autores).

O loteamento São Cristóvão, na porção

Sul da malha urbana local, possui $116.146,58 \mathrm{M}^{2}$ de área total, e 193 terrenos, sendo destes, 186 terrenos destinados a residências, além de $11.714,83 \mathrm{M}^{2}$ de área destinada à áreas verdes.

Scatola, M. A. G., Tomazoni, J. C. 
O loteamento Lago das Torres, na porção Leste da malha urbana de Francisco Beltrão, possui 178.394,00 $\mathrm{M}^{2}$ de área total, sendo 181 lotes e 71.257,62 M² de áreas verdes.

Já o Loteamento localizado ao Norte da malha urbana local, denominado Marchiori, possui 98.678,69 M² de área total, com 164 lotes, e 9.943,00 M² em áreas verdes

\section{Resultados e discussão}

\section{Resultado da análise do indicador Terra Urbana:}

\section{Declividade, erosão e restrição de uso}

Uma das principais condicionantes analisadas quando se trata da terra urbana, são as características específicas do sítio quanto à relação entre sua declividade, e espaços suscetíveis à erosão e restrição de uso, temas que são apresentados com os mapas de declividade dos loteamentos, conforme figura 02 .

Conforme diretriz do Estatuto da Cidade e também do Plano Diretor de Francisco Beltrão, não pode ocorrer o parcelamento do solo em áreas com inclinação igual ou superior a 30\%. Ao mesmo tempo, Santos (2004) cita que uma análise da declividade da terra urbana, permite inferir informações como forma de paisagem, erosão, potencialidade de uso, manejo e práticas de conservação, dentre outros.

Neste indicador, percebe-se que no Loteamento São Cristóvão, 07 terrenos foram dispostos em áreas com declividade entre 25 e 50\%; no Loteamento Marchiori, 03 terrenos se encontram na mesma situação, e no Loteamento Lago das Torres, nenhum terreno foi implantado em área acima de $30 \%$ de declividade, que caracteriza uma restrição de uso para uma urbanização adequada.

Outra restrição de uso é a implantação de loteamentos em topos de morro acima de 20 metros do logradouro lindeiro o que significa que a via de acesso principal do loteamento não pode estar em cota de nível abaixo de 20 metros da altitude do próprio loteamento. No Loteamento São Cristóvão, a Rua Pato Branco, que dá acesso ao mesmo, existia antes da implantação do loteamento, e embora tenha grande declividade, está atendendo á legislação neste sentido.

Já quanto a características de erosão do solo, o que ocorre quando a erosão da terra urbana é gerada com a desestabilização entre o solo e seus componentes e a ausência de vegetação (Santos, 2004), percebe-se que a mesma ocorre nas áreas limítrofes do Loteamento São Cristóvão, o qual foi implantado em área de topo de morro, e também no Loteamento Marchiori, em sua parte mais alta, que possui maior declividade, e que se configura como uma encosta que foi parcialmente modificada,conforme se percebe nas figuras 03 e 04. 
Revista Brasileira de Geografia Física v.11, n.04 (2018) 1609-1627.
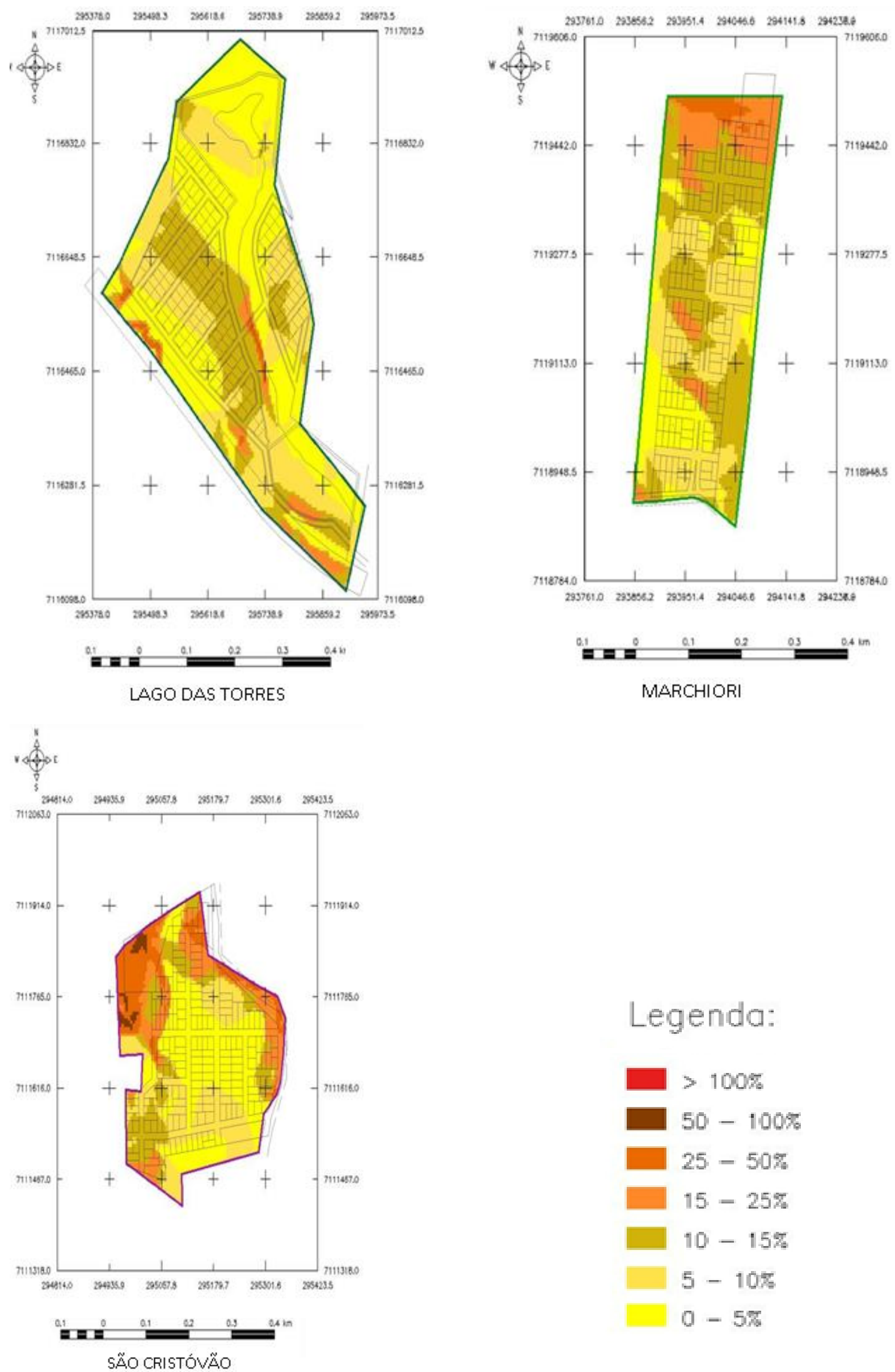

Legenda:

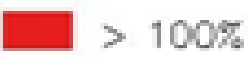

प $50-100 \%$

$25-50 \%$

$15-25 \%$

$10-15 \%$

$5-10 \%$

$0-5 \%$

Figura 02: Mapas de declividade dos loteamentos estudados.

Scatola, M. A. G., Tomazoni, J. C. 
Fonte: Secretaria de Urbanismo da PMFB, editado pelos autores.

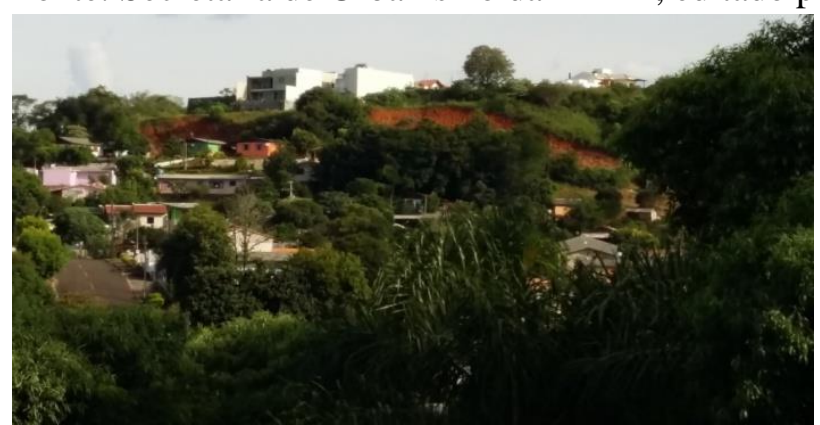

Figuras 03 - Erosão nos loteamentos São Cristóvão. Fonte: Foto tirada pelos autores.

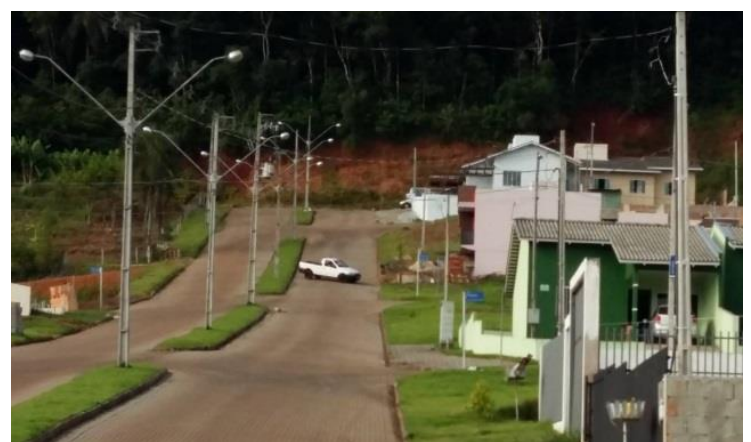

Figuras 04: Erosão nos loteamentos Marchiori. Fonte: Foto tirada pelos autores.

\section{Resultado da análise do indicador Moradia: Lotes}

Quanto à morfologia dos lotes, em todos os loteamentos foi adotado o esquema de tabuleiro de xadrez para a disposição dos terrenos, priorizando as vias de circulação e visando um aproveitamento máximo do sítio. Os lotes com formas irregulares, todavia, em todos os loteamentos foram dispostos nas áreas menos favorecidas sobretudo devido à declividade do sítio, sendo esta uma característica favorável quanto à sustentabilidade urbana, pois favorece na implantação das edificações e possibilita o aumento da áreas permeáveis dos terrenos.

Tabela 02- Resultado da análise da morfologia dos lotes

\begin{tabular}{|c|c|c|c|}
\hline $\begin{array}{c}\text { Loteament } \\
\text { o }\end{array}$ & $\begin{array}{l}\text { Tota } \\
1 \text { de } \\
\text { lotes }\end{array}$ & $\begin{array}{l}\text { Lotes com } \\
\text { forma } \\
\text { regular }\end{array}$ & $\begin{array}{l}\text { Lotes com } \\
\text { forma } \\
\text { irregular }\end{array}$ \\
\hline São & 193 & $169(87,5 \%$ & $24(12,4 \%)$ \\
\hline Cristóvão & & ) & \\
\hline $\begin{array}{l}\text { Lago das } \\
\text { Torres }\end{array}$ & 181 & 149(82,3\% & $\begin{array}{c}32(17,67 \% \\
)\end{array}$ \\
\hline Marchiori & 164 & $161(98,1 \%$ & $03(0,1 \%)$ \\
\hline
\end{tabular}

Fonte: Dados analisados através do mapa de declividade, organizados pelos autores.

\section{Resultado da análise do indicador Saneamento Ambiental: atendimento por sistema adequado de esgotamento sanitário}

Dentro do contexto do saneamento ambiental, optou-se por analisar o indicadorreferente ao atendimento por rede adequada de esgotamento sanitário. Este indicador se faz muito importante, uma vez que um esgotamento sanitário adequado diminui as chances de contaminação do solo e das águas, melhorando consideravelmente a qualidade de vida da população, bem como as condições de sustentabilidade locais, e os resultados podem ser verificados na tabela 03 .

Tabela 03- Resultado da pesquisa sobre sistema de esgotamento sanitário.

\begin{tabular}{c|c|c|c|c}
\hline Loteamento & $\begin{array}{c}\text { Residências } \\
\text { pesquisadas }\end{array}$ & $\begin{array}{c}\text { Atendimento por rede } \\
\text { de coleta de esgoto }\end{array}$ & $\begin{array}{c}\text { Esgotamento sanitário } \\
\text { por fossa séptica }\end{array}$ & Outro \\
\hline São Cristóvão & 80 & $56 \%$ & $44 \%$ & - \\
Lago das Torres & 95 & $5,55 \%$ & $90,4 \%$ & $4 \%$ \\
Marchiori & 80 & - & $100 \%$ & - \\
\hline
\end{tabular}

Fonte: Dados obtidos na Secretaria de Urbanismo da Prefeitura Municipal. (Organizado pelos autores).

Os dados coletados e expressos na tabela 03, se justificam quando comparados ao mapeamento da rede de coleta de esgotos que

Scatola, M. A. G., Tomazoni, J. C. atende aos loteamentos deste estudo. Percebe-se que os percentuais expressos na tabela correspondem ao número de residências que são 
atendidas por rede coletora nos loteamentos, ou mesmo possuem destinação final dos resíduos sólidos através de fossa séptica. No caso do Loteamento Marchiori, este ainda não possui a passagem da rede coletora de esgoto, o que explica $100 \%$ da destinação final dos resíduos sólidos do loteamento, estar sendo realizada através de fossa séptica.

\section{Resultado da análise do indicador Infraestrutura}

\section{Urbana: Iluminação Pública}

A fim de analisar a existência e a adequação da iluminação pública nos loteamentos Tabela 04- Resultado da pesquisa sobre iluminação pública

\begin{tabular}{c|c|c|c|c}
\hline Loteamento & Total de vias & $\begin{array}{c}\text { Vias com } \\
\text { iluminação } \\
\text { pública }\end{array}$ & $\begin{array}{c}\text { Percentual de vias com } \\
\text { iluminação pública }\end{array}$ & $\begin{array}{c}\text { Distâncias médias entre } \\
\text { os pontos de } \\
\text { iluminação }\end{array}$ \\
\hline São Cristóvão & 11 & 11 & $100 \%$ & $45 \mathrm{~m}$ \\
Lago das Torres & 15 & 15 & $100 \%$ & $40 \mathrm{~m}$ \\
Marchiori & 10 & 10 & $100 \%$ & $39 \mathrm{~m}$ \\
\hline
\end{tabular}

Fonte: Dados levantados em campo. (Organizado pelos autores).

em estudo, realizou-se um levantamento de dados através de pesquisa de campo, sendo possível assim confeccionar a tabela 04 .

Como se pode perceber, todos os loteamentos possuem $100 \%$ das vias com iluminação pública, e todos possuem os pontos de distribuição de iluminação dentro da distância mínima recomendada para postes convencionais, que é de 30 a 45 metros para postes com iluminação pública convencional, de acordo com Mascaró e Yoshinaga (2013).
Resultado da análise do indicadorTransportes: utilização de meio de transporte público coletivo $e$ de meios não motorizados de transporte

\begin{abstract}
O resultado da análise destes indicadores, na categoria transporte, demonstram que ainda
existem grandes entraves para a implementação de
meios de transporte e locomoção sustentáveis
relacionados à mobilidade urbana, conforme
demonstram dados das tabelas 05 e 06 . na categoria transporte, demonstram que ainda
existem grandes entraves para a implementação de
meios de transporte e locomoção sustentáveis
relacionados à mobilidade urbana, conforme
demonstram dados das tabelas 05 e 06 . na categoria transporte, demonstram que ainda
existem grandes entraves para a implementação de
meios de transporte e locomoção sustentáveis
relacionados à mobilidade urbana, conforme
demonstram dados das tabelas 05 e 06 . na categoria transporte, demonstram que ainda
existem grandes entraves para a implementação de
meios de transporte e locomoção sustentáveis
relacionados à mobilidade urbana, conforme
demonstram dados das tabelas 05 e 06 . na categoria transporte, demonstram que ainda
existem grandes entraves para a implementação de
meios de transporte e locomoção sustentáveis
relacionados à mobilidade urbana, conforme
demonstram dados das tabelas 05 e 06 .
\end{abstract}

Tabela 06- Resultado da pesquisa sobre utilização de meio de transporte não motorizado

\begin{tabular}{|c|c|c|}
\hline Loteamento & $\begin{array}{c}\text { Percentual de moradores que utilizam } \\
\text { bicicleta para atividades cotidianas }\end{array}$ & $\begin{array}{c}\text { Percentual de moradores que caminham a } \\
\text { pé no loteamento ou para sair do mesmo }\end{array}$ \\
\hline
\end{tabular}

Tabela 05- Resultado da pesquisa sobre utilização do transporte público coletivo

\begin{tabular}{l|l|l}
\hline Loteamento & $\begin{array}{l}\text { Percentual } \\
\text { de } \\
\text { moradores } \\
\text { que utilizam } \\
\text { o transporte } \\
\text { público } \\
\text { coletivo }\end{array}$ & $\begin{array}{l}\text { Percentual de } \\
\text { moradores que } \\
\text { não utilizam o } \\
\text { transporte } \\
\text { público } \\
\text { coletivo }\end{array}$ \\
& \multicolumn{1}{c}{$4 \%$} & $96 \%$ \\
\hline $\begin{array}{l}\text { São Cristóvão } \\
\text { Lago das } \\
\text { Torres } \\
\text { Marchiori }\end{array}$ & $25 \%$ & $75 \%$ \\
\hline
\end{tabular}

Fonte: Dados coletados em campo. (Organizado pelos autores).

Scatola, M. A. G., Tomazoni, J. C. 
Revista Brasileira de Geografia Física v.11, n.04 (2018) 1609-1627.

\begin{tabular}{|c|c|c|c|c|}
\hline & Sempre & $\begin{array}{c}\text { Raramente } \\
\text { ou nunca }\end{array}$ & Sempre & $\begin{array}{c}\text { Raramente ou } \\
\text { nunca }\end{array}$ \\
\hline São Cristóvão & - & $100 \%$ & $12 \%$ & $88 \%$ \\
\hline Lago das Torres & $11 \%$ & $89 \%$ & $25 \%$ & $75 \%$ \\
\hline Marchiori & $12 \%$ & $88 \%$ & $12 \%$ & $88 \%$ \\
\hline
\end{tabular}

Fonte: Dados coletados em campo. (Organizados pelos autores).

Resultado da análise do indicador Serviços Públicos e Lazer: análise da oferta de equipamentos públicos e de serviços cotidianos

Um bairro completo, bem servido de equipamentos públicos e de serviços dos quais as pessoas possam necessitar no dia a dia, geralmente é sinônimo de um local com qualidade de vida e com sustentabilidade, trazendo diversos benefícios, dentre os quais se pode citar a diminuição das distâncias de deslocamento e consequente melhora nos índices de mobilidade urbana. Para esta análise, foram confeccionados os mapas de equipamentos e serviços dos bairros, que constam nas figura 05,06 e 07 , nos quais se localizam os loteamentos em estudo, e comparada as suas localizações com relação aos loteamentos.
Percebe-se que os bairros estão bem servidos de equipamentos públicos e espaços de serviços e comércio cotidianos, porém quando se compara a localização destes equipamentos e serviços com as distâncias de caminhamento (Farr, 2013), ou raios de abrangência, há uma defasagem. O Loteamento São Cristóvão é atendido de forma mais aproximada, por equipamento de saúde e espaço de compartilhamento de automóveis; o Loteamento Lago das Torres é atendido de forma mais aproximada, por equipamento de saúde e locais para culto; o Loteamento Marchiori é atendido de forma mais aproximada, por equipamento de saúde e bancos. Os demais equipamentos localizam-se em pontos cujo acesso a partir dos loteamentos é mais difícil.

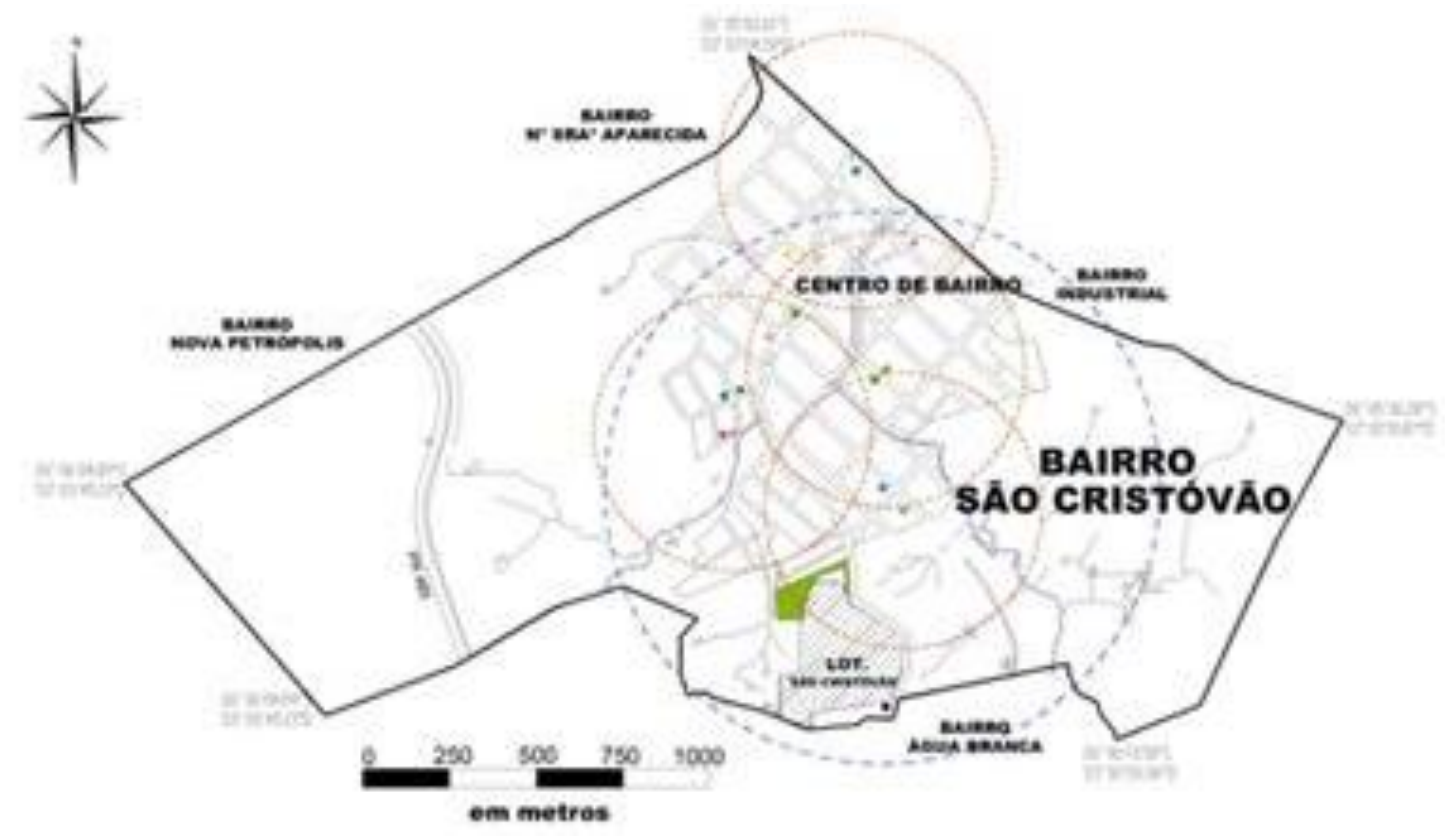

Scatola, M. A. G., Tomazoni, J. C. 


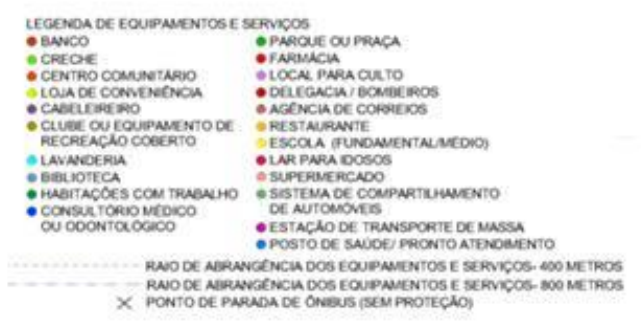

Figura 05: Mapas de equipamentos dos bairros São Cristóvão. Fonte:Secretaria de Urbanismo da Prefeitura Municipal, e dados de campo. (Organizado pelos autores).
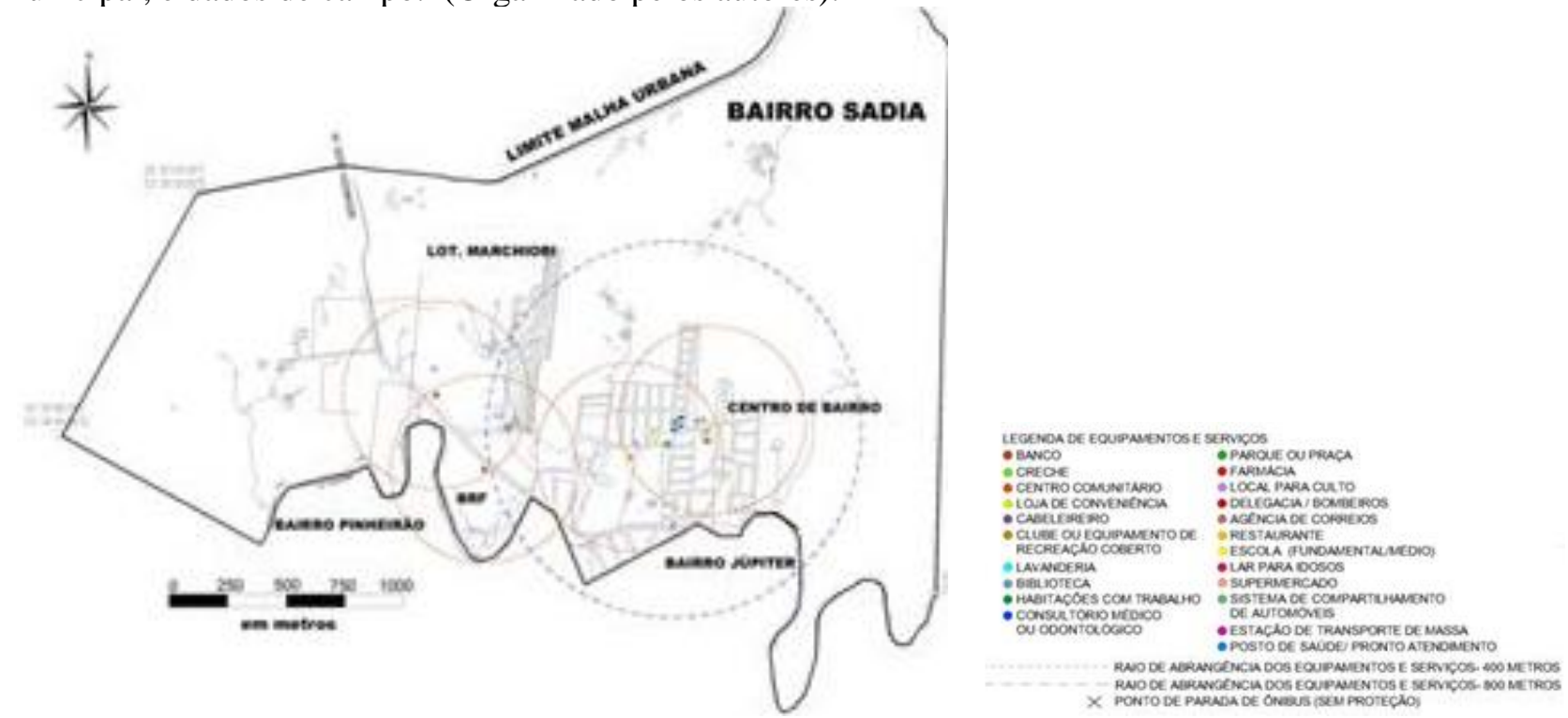

Figura 06: Mapas de equipamentos dos bairros Sadia. Fonte:Secretaria de Urbanismo da Prefeitura Municipal, e dados de campo. (Organizado pelos autores).

Scatola, M. A. G., Tomazoni, J. C. 

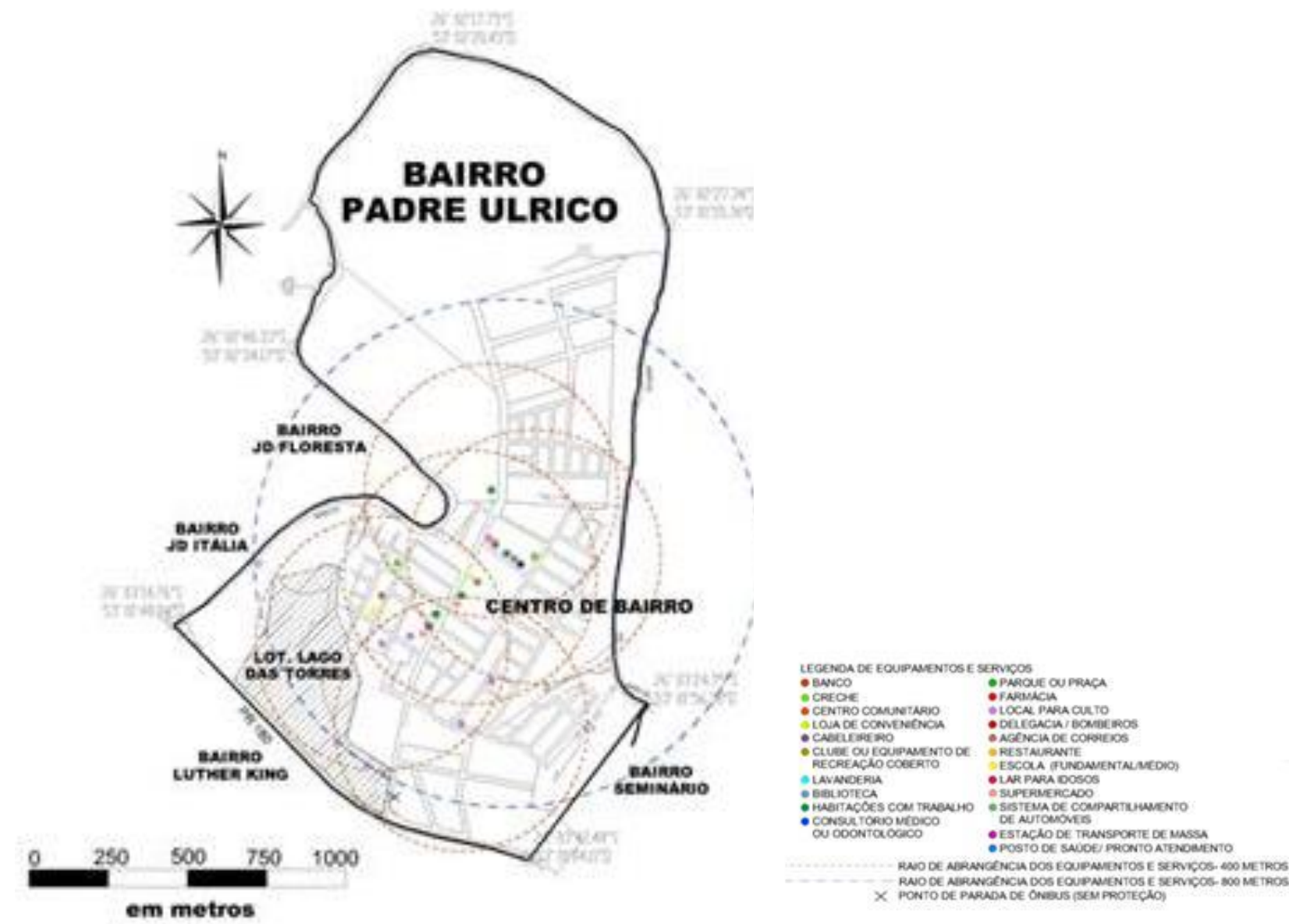

Figura 07: Mapas de equipamentos do bairro Padre Ulrico. Fonte:Secretaria de Urbanismo da Prefeitura Municipal, e dados de campo. (Organizado pelos autores).

\section{Conclusão}

Compreender e aplicar a sustentabilidade urbana em novas áreas de expansão urbana das cidades atuais, é importantepara que as cidades se tornem locais com maior qualidade de vida, com sistemas, espaços e ações mais duráveis e eficazes, proporcionando um desenvolvimento econômico que esteja ao lado de questões ambientais e sociais, firmando os pilares da sustentabilidade.

É no meio urbano onde ocorre grande parte das transformações idealizadas pelo homem junto ao espaço natural, por isso se faz fundamental que a sustentabilidade urbana seja pesquisada, definida, aplicada e identificada, principalmente junto a novas áreas de expansão territorial urbana, como são os loteamentos, pois nestes espaços há a possibilidade plena de um correto planejamento antes da real execução da expansão urbana.

À medida que a cidade de Francisco Beltrãofirmou sua importância como centro regional, também sua população aumentou, e com isso se deu a necessidade por novos espaços urbanos, sobretudo através de novos loteamentos. A expansão territorial urbana da cidade durante a década de 2000 foi expressiva, e com isso surge a necessidade de averiguar se essa expansão seguiu as caracterizações de sustentabilidade recomendadas pelo Estatuto da Cidade, as quais devem estar dispostas junto às diretrizes do Plano Diretor Municipal, e desta forma, também executadas junto às áreas de expansão urbana locais. 
De maneira geral, após a obtenção dos resultados da análise dos indicadores de sustentabilidade, percebe-se que diversas categorias de sustentabilidade pesquisadas apontaram resultados aquém do que seria esperado, apresentando alguns problemas nos loteamentos, por exemplo, com relação à utilização inadequada da terra urbana, carência de saneamento ambiental adequado, mesmo em loteamentos considerados de médio/alto padrão social, deficiências no transporte, através da falta de adequabilidade das condições de mobilidade urbana, e carência na existência e localização espacial de alguns equipamentos urbanos. Por outro lado, na categoria infraestrutura, a iluminação pública foi considerada adequada, pois se encontra dentro dos padrões esperados, de acordo com a bibliografia utilizada.

Se faz importante citar também da importância da formulação de indicadores de sustentabilidade adequados, de acordo com cada categoria de sustentabilidade que deve ser aplicada, de acordo com o Estatuto da Cidade, observando as particularidades do local onde se avalia determinada categoria. A sustentabilidade deve ser local, pois condicionantes econômicos, físicos, ambientais e socioculturais interferem no resultado que se espera da avaliação de sustentabilidade, por isso nem sempre os indicadores podem ser aplicados através de índices precisos, mas sim através de uma análise qualitativa.

Dentro de uma cidade, existem realidades distintas, por isso uma análise por bairros, ou mesmo por loteamentos, se faz fundamental a fim de compreender quais são as condições de sustentabilidade urbana existentesdentro do todo de determinado espaço urbano.

\section{Agradecimentos}

Agradecemos ao Programa de Pós-graduação em Desenvolvimento Regional-PPGDR, da UTFPRUniversidade Tecnológica Federal do Paraná, pelo apoio para o desenvolvimento deste estudo.

\section{Referências}

Benitez, R.M.,1998.O capital social fixo como insumo do desenvolvimento regional. Revista Econômica do Nordeste [online] 29.Disponível:https://www.bnb.gov.br/projweb ren/Exec/artigoRenPDF.aspx?cd_artigo_ren=84 . Acesso: 06 abr. 2017.

Braga, R., 2012. O Estatuto da Cidade como instrumento de desenvolvimento sustentável para as cidades brasileiras: possibilidades e limites. Disponível: http://www.rc.unesp.br/igce/planejamento/dow nload/RobertoBraga/artig_pluris2012.pdf. Acesso: 06 abr. 2017.

BRASIL, 1988. Constituição da República Federativa do Brasil,de 05 de outubro.

BRASIL, 2001. Lei $\mathrm{n}^{\circ} 10.257$, de 10 de julho.

BRASIL, 2007. Lei $\mathrm{n}^{\circ} 11.445$, de 05 de janeiro.

Choay, F.,2010. O Urbanismo, 3 ed.Perspectiva, São Paulo.

Corrêa, R.,1995. O Espaço Urbano, 3 ed. Ática, São Paulo.

Duarte, F.,2011. Planejamento Urbano,2ed. Ibpex, Curitiba.

Farr, D.,2013. Urbanismo Sustentável: Desenho urbano com a natureza, 1 ed.Bookman, Porto Alegre.

Fresca, T. M.,2010.Centros locais e pequenas cidades: diferenças necessárias. Mercator [online] número especial. Disponível em: http://www.periodicos.ufc.br/mercator/article/vi ew/700/677. Acesso: 07 abr. 2017.

Koga, D.,2011.Medidas de cidades: entre territórios de vida e territórios vividos, 2 ed. Cortez, São Paulo.

Lamas, J.,2014.Morfologia urbana e desenho da cidade,7 ed. Fundação CalousteGulbenkian, Lisboa.

Leite, C.,Awad, J.,2012. Cidades Sustentáveis, Cidades Inteligentes: desenvolvimento sustentável num planeta urbano, 1 ed.Bookman,Porto Alegre. 
Manzano, E. R., 2006. A iluminação artificial do recinto urbano, in: Mascaró, L. (Org.), A iluminação do espaço urbano.Masquatro, Porto Alegre, pp. 21-26.

Mascaró, J. L.,2005.Loteamentos urbanos,2 ed. Masquatro, Porto Alegre.

Mascaró, J .L., Yoshinaga, M.,2013.Infraestrutura Urbana. JMascaró, Porto Alegre.
MINISTÉRIO DAS CIDADES, 2004.Agenda 21 brasileira: ações prioritárias.Disponível: http://www.ebah.com.br/content/ABAAAfH6U AG/agenda-21-brasileira-acoesprioritarias?part=3. Acesso: 06 abr. 2017.

Santos, R.,2004.Planejamento Ambiental: teoria e prática, 1 ed. Oficina de Textos, São Paulo.

Veiga, J., 2010.Indicadores de sustentabilidade. Estudos Avançados [online] 24.

Disponível:

http://www.scielo.br/scielo.php?script=sci_artte xt\&pid=S0103-40142010000100006. Acesso: 10 mar. 2017. 